\title{
A COMPARATIVE STUDY ON ACHIEVEMENT MOTIVATION BETWEEN UNDER GRADUATE AND POST GRADUATE STUDENTS
}

KEY WORDS: Achievement Motivation, Physical Education

\section{Sunita Singh Sports Officers, Sudarshan Degree College, Lalgaon}

AIM: The Purpose of the study was to compare the degree of Achievement Motivation between Under Graduate and Post Graduate students.

METHODS: The study was delimited to the thirty players (fifteen student in each discipline) who had study in Sudarshan

E Degree College, Lalgaon were selected randomly as the subjects for the study. The age of the subjects were ranging from 17 - 21 years. The Study was further delimited to the assessment of Achievement Motivation by using Sports Achievement Motivation Test (SAMT) prepared by M.L. Kamlesh. It was hypothesized that there would be no significant a difference between the Under Graduate and Post Graduate students on the Achievement Motivation. For the purpose of analysis of data ' $t$ ' test was employed to compare the Achievement Motivation between Under Graduate and Post Graduate students.

RESULT: There was an insignificant difference between the means of Under Graduate and Post Graduate students on the scores of Achievement Motivation since the obtained value of ' $t$ ' (1.05) was lower than the tabulated value.

CONCLUSION: The Achievement Motivation of PG was found to be higher than the UG students.

\section{INTRODUCTION}

All sports is psychological as well as physical because, it is led by mental images and thought patterns. It will, however allow you to draw the most from the conditioning you have. If you have trained more and better, your present capacity will be higher than if you have trained less, your performance will be less well. However, regardless of what your physical capacity might be at moment, you have to look at your psyche in order to get the most from what you have. You have to rely on your head and your thoughts, images and mental patterns to act as the controlled mechanism. Negative thoughts are particularly effective for destroying skilled performance. (Teri Orlic 1966)

Sport psychology is about winning, because it focuses on understanding how athletes succeed and assisting athletes and coaches in achieving their best performance. But it is about much more than that. It is about learning how good one are and discovering how far one can go. It is about the joys of teamwork and striving for a team goal that is greater than any individual goal; it is about enjoying each moment because neither success nor failure is permanent, so if the journey isn't worthwhile, the destination isn't work reaching. It is about the wonders of self-discovery, learning to understand how you respond to pressure and how one can make yourself better everyday by learning from your experience. Let the voyage begin. ( Shane Murphy 2005)

During the last few decades, coaches and athletes from a wide variety of sports have begun to realize the importance of the mental side of athletic performance. More specifically, individuals involved with organized sport now understand that for athletes to perform at their peak level of efficiency, they must possess and use a number of psychological skills. This is also true within the world of sports as coaches and athletes have become interested in enhancing their athletes' psychological skills (Caudill, Weinberg, \& Jackson, 1983; Ungerleider \& Golding, 1991). For instance, articles appearing in Track Coach have discussed the importance of the mental preparation (e.g., Anderson, 1997; Sing, 1986; Vernacchia, 1997; Yingbo, 1992).

Sports psychology is a science in which the principle of psychology is applied in a sports or exercise setting. These principles are often applied to enhance performance. The true sports psychologist is interested in much more their performance enhancement and sports as a vehicle for human enhancement. The sports psychologist is interested in helping every sport participant reach his or her as an athlete. Sports psychology is an exciting subject dedicated to the enhancement of both athletic performance and social psychological aspect of human enrichment. ( Richard. H.

\section{Cox, 2002)}

\section{METHODS}

The Purpose of the study was to compare the degree of Achievement Motivation between Under Graduate and Post Graduate students.

The study was delimited to the thirty players (fifteen students in each discipline) who had study in Sudarshan Degree College, Lalgaon were selected randomly as the subjects for the study. The age of the subjects were ranging from $17-21$ years. The study was further delimited to the assessment of Achievement Motivation by using Sports Achievement Motivation Test (SAMT) prepared by M. L. Kamlesh. It was hypothesized that there would be no significant a difference between the Under Graduate and Post Graduate students on the Sports Carriers.

It was hypothesized that there would be no significant a difference between the Under Graduate and Post Graduate students on the Sports Carriers.

\section{SPORTS ACHIEVEMENT MOTIVATIONTEST (SAMT) PURPOSE: -}

The purpose of Sports Achievement Motivation Test (SAMT) is a self-evaluation test used to assess the level of sports achievement motivation of the players.

\section{PROCEDURE:-}

The SAMT questionnaire has twenty statements. Every statement has two propose part. The subjects complete each incomplete sentence with the help of marking one of the given two parts.

The examples of SAMTn of inventory are following:

l.I enjoying playing (a) vigorous game(s).

(b) Game which require little physical efforts.

2. As a player I like to be called (a) a well skilled.

(b) a top performer.

\section{SCORING:}

Each statement carries a maximum of two and the minimum zero. The Response value of the total questionnaire extends from 0 to 40 in total. The test of motivation achievement depends upon the total score obtained.

Raw

$0-24$

24-30

$30-40$

Classification
Low
Moderate
High


For the purpose of analysis of data ' $t$ ' test was employed to compare the degree of Achievement Motivation between Under Graduate and Post Graduate students.

FINDINGS

TABLE -1 SIGNIFICANT DIFFERENCE OF MEAN ON ACHIEVEMENT MOTIVATION BETWEEN UNDER GRADUATE AND POST GRADUATE STUDENTS

\begin{tabular}{|c|c|c|c|c|c|c|}
\hline \multirow{2}{*}{ Variable } & \multicolumn{2}{|c|}{ Mean } & \multicolumn{2}{c|}{ S.D } & \multirow{2}{*}{ Mean Diff. } & \multirow{2}{*}{ t-Ratio Diff } \\
\cline { 2 - 5 } & U.G. Students & P.G. Students & U.G.Students & P.G. Students & & \\
\hline $\begin{array}{c}\text { Achievement } \\
\text { Motivation }\end{array}$ & 28.80 & 32.00 & 4.23 & 3.12 & 1.20 & 1.05 \\
\hline
\end{tabular}

*Significant at .05 level of confidence

$\mathrm{t}_{05}(28)=2.048$

6. Richard. H. Cox, "Sports Psychology Concepts and Application" (Mc. Graw Hill Publication, New York, 5th Edition 2002), pp. 4-5.

7. Shane Murphy,"The Sport Psych Handbook”"(Human Kinetics, 2005), pp. 14-15.

8. Teri Orlic, "Psyching for Sports"(Illinois Leisure Press, 1966), p. 90.

It is evident from Table-1 that there was an insignificant difference between the means of the Under Graduate and Post Graduate students on the Achievement Motivation since the obtained value of ' $t$ ' (1.05) was lower than the tabulated value of ' $t$ ' (2.048) which was required to be significant at (28) degree of freedom with 0.05 level of confidence.

The graphical representation of mean and standard deviation of Achievement Motivation between Under Graduate and Post Graduate students has been presented in figure 1.

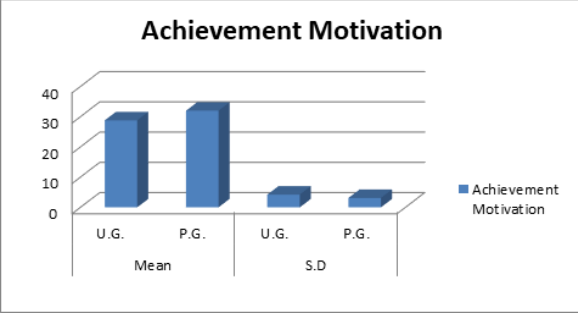

Figure 1-Comparison of Mean Scores between Under Graduate and Post Graduate Students on Achievement Motivation

\section{DISCUSSION OF FINDINGS}

The mean value (32) of PG students on Achievement Motivation was found to be higher than the UG students (28.80), which revealed that PG students were more Achievement Motivation in comparison to the UG students. Statically there was no significant difference between UG and PG students in achievement motivation during the comp etition.

According M L Kamlesh in sports Achievement Motivation, perusals of mean score of PG Student have high level of achievement motivation whereas UG Students were characterized with moderate level of achievement motivation at the time of competition.

\section{DISCUSSION OF HYPOTHESIS}

The hypothesis that there will be a no significant difference between the Under Graduate and Post Graduate students on the Achievement Motivation is rejected.

\section{CONCLUSIONS}

1. In regard to Achievement Motivation there was an insignificant difference between the means of Under Graduate and Post Graduate students.

2. The Achievement Motivation level of PG students was found to be higher than the UG students.

\section{REFERENCE:}

1. Brayanat J.Cratty, Psychology in Contemporary Sport, Guidelines for Coaches and Athletes (U.S.A.:Englewood Cliffs, 1983), P 106

2. Cal E. Kalfs and Caniel D.Arutheim. Modern Principles of Athletics Training (St.Louis: C.V.Mosby Company, 1969),p.117.

3. Ibrahim, Milmi and Morrison, Netie "Self Actualization and Achievement Motivation Among Athletes," Research Quarterly 47 (May 1976).

4. Kamlesh, M.L., Psychology in Physical Education and Sports (New Delhi: Metropolitan Book Co.Pvt.Ltd., 1987), p.273.

5. Mahoney J.M. and Avener, K., "Psychology of the Elite Athlete," An Exploratory Study, Cognitive Therapy and Research l (1977). 